\title{
Re: Comparison of Vasovasostomy with Conventional Microsurgical Suture and Fibrin Adhesive in Rats
}

\author{
Wilson F. Busato Junior, Amandia M. Marquetti, Luiz C. Rocha
}

Section of Urology (WFBJ), School of Medicine, UNIVALI and Catarinense Institute of Urology (WFBJ, AMM), Itajai, Santa Catarina, Section of Urology (LCR), School of Medicine, Federal University of Parana, Curitiba, Brazil

Int Braz J Urol. 33: 829-36, 2007

To the Editor,

We read with great interest the paper by Wilson F. Busato Junior and colleagues (1). In this elegant study two techniques of vasovasostomy have been tested in a laboratory setting. One group of rats underwent "conventional" one-layer anastomosis on the left vas deferent, after transection on the right side; another group was evaluated for a simplified anastomosis performed with one anchor point plus fibrin glue, and the last group served as control after a sham operation. The authors concluded that the two techniques are similar $(p>0.05)$ and the operative time is the only relevant difference.

As a first point to debate we would emphasize that the results of this study cannot be considered out of an experimental concern. This is because the anastomosis was performed using perfect stumps of deferens and they were immediately reattached after cutting. Thus, it does not reproduce the real clinical condition in which a scar tissue can be found at the cut ends.

Another issue refers to the way of apposing the divided ends of the vasa. The authors applied a direct end-to-end anastomosis in both procedures. However, in a clinical context, it might be helpful a modified approach based on preparing the vas ends. As reported by Fox, the convoluted portion of the vas is always thinner and more difficult to suture than the straight part. Therefore, in all cases in which the stumps are of different size, it is advantageous to transect obliquely the deferent in order to augment the diameter of its lumen (2). This technique has shown ensuing paternity in one third of patients either after primary or revised vasovasostomy.

Finally, the authors suggest that the fibrinsupplied vasovasostomy since requires less operative time may became a simplified procedure suitable also for a general urologist. Nevertheless the microsurgical vasovasostomy performed at microscope is widely considered improved over other methods using less magnification (3). Thus, in our opinion the vasovasostomy should preferably address to urologists trained in microsurgery (clinical or experimental) or practiced in dedicated centers.

In any case, we congratulate the authors for a well drawn study dealing with appropriate number of animals according to modern ethical rules (4).

\section{REFERENCES}

1. Busato WF Jr, Marquetti AM, Rocha LC: Comparison of vasovasostomy with conventional microsurgical suture and fibrin adhesive in rats. Int Braz J Urol. 2007; 33: 829-36.

2. Fox M: Easing the technical difficulty of microscopic vasectomy reversal. Br J Urol. 1996; 78: 462-3.

3. Fox M: Failed vasectomy reversal: is a further attempt using microsurgery worthwhile? BJU Int. 2000; 86: 474-8.

4. Hagelin J, Carlsson HE, Hau J: Increased efficiency in use of laboratory animals. Lancet. 1999; 353: 1191-2.

Dr. Fabio Campodonico \& Dr. Antonio Casarico Department of Urology EO Ospedali Galliera Genova, Italy E-mail: fabio.campodonico@galliera.it 


\title{
Re: Sperm Defect Severity Rather than Sperm Source is Associated with Lower Fertilization Rates after Intracytoplasmic Sperm Injection
}

\author{
Sidney Verza Jr, Sandro C. Esteves \\ Androfert, Center for Male Reproduction, Campinas, Sao Paulo, Brazil
}

Int Braz J Urol, 34: 49-56, 2008

To the Editor,

I sincerely hope that I may be permitted to comment on a very important issue in the male factor infertility aspect: the male gamete and its role in the outcome of intracytoplasmic sperm injection (ICSI). We read with interest the article published by Verza and Esteves entitled: "Sperm defect severity rather than sperm source is associated with lower fertilization rates after intracytoplasmic sperm injection" (1).

In the past, we had the opportunity to publish 2 articles regarding this issue $(2,3)$. One of these articles we reported that the pregnancy rates is significantly lower in patients with non-obstructive azoospermia compared to patients with obstructive azoospermia (1). In the other article, we detected higher fertilization and implantation rates seen in azoospermic patients from congenital causes of obstruction. In addition, epididymal sperm results in higher pregnancy rates and lower miscarriage rates compared to testicular spermatozoa (3).

In fact, various factors may influence the outcome of ICSI in azoospermic patients. These include parameters linked to male partner - such as serum FSH and testicular histology - that may reflect upon the quality of the surgically retrieved sperm cells.

The authors evaluated one very interesting issue that has been left apart from the other articles published regarding the outcome of ICSI with the use of sperm from different etiologies. The quality of the semen is very important and not only the origin of the sperm retrieved. In the past, Nagy et al demonstrated that, irrespective the source of the semen, the outcome using ICSI is the same (4). Additionally, Svalander et al., demonstrated that sperm morphology according to the strict criteria is not related to the ICSI outcome (5). However, this is not completely true. In clinical practice, the quality of the semen does matter. The worst the semen quality, the worst outcome result. This emphasizes the role of the urologist in order to improve semen quality instead of referring this patient for assisted reproduction without any sort of urological treatment before. Our role of urologists is to try to improve semen quality, for instance, operate varicoceles, perform vasectomy reversals, etc.

Once again, as a urological community, we thank such important article.

\section{REFERENCES}

1. Verza S Jr, Esteves SC: Sperm defect severity rather than sperm source is associated with lower fertilization rates after intracytoplasmic sperm injection. Int Braz J Urol. 2008; 34: 49-56.

2. Pasqualotto FF, Rossi-Ferragut LM, Rocha CC, Iaconelli A Jr, Borges E Jr: Outcome of in vitro fertilization and intracytoplasmic injection of epididymal and testicular sperm obtained from patients with obstructive and nonobstructive azoospermia. J Urol. 2002; 167: 1753-6.

3. Pasqualotto FF, Rossi LM, Guilherme P, Ortiz V, Iaconelli A Jr, Borges E Jr: Etiology-specific outcomes of intracytoplasmic sperm injection in azoospermic patients. Fertil Steril. 2005; 83: 606-11.

4. Nagy Z, Liu J, Cecile J, Silber S, Devroey P, Van Steirteghem A: Using ejaculated, fresh, and frozen- 


\section{Letter to the Editor}

thawed epididymal and testicular spermatozoa gives rise to comparable results after intracytoplasmic sperm injection. Fertil Steril. 1995; 63: 808-15.
5. Svalander P, Jakobsson AH, Forsberg AS, Bengtsson $\mathrm{AC}$, Wikland M: The outcome of intracytoplasmic sperm injection is unrelated to 'strict criteria' sperm morphology. Hum Reprod. 1996; 11: 1019-22.

Dr. Fabio Firmbach Pasqualotto Professor of Anatomy and Urology University of Caxias do Sul, RS, Brazil Caxias do Sul, RS, Brazil E-mail:fabio@conception-rs.com.br

Dr. Edson Borges Jr Fertility, Center for Assisted Fertilization São Paulo, SP, Brazil E-mail:edson@fertility.com.br 